\title{
Escovando a história a contrapelo: a desaceleração da modernidade em Walter Benjamin
}

Georg Otte (UFMG/CNPq/ZfL ${ }^{1}$ )

Resumo: O pensamento de Walter Benjamin é marcado por pares de opostos, tais como proximidade/distância, concentração/dispersão, singularidade/multiplicação, dinamismo/inércia etc. $\mathrm{O}$ presente ensaio procura mostrar que essas polarizações fazem parte de uma dialética fecunda, porém não sintetizante. A "dialética em suspensão" de Benjamin não costura as rupturas existentes na modernidade, mas evidencia suas tendências antagônicas.

Palavras-chave: Modernidade, desaceleração.

É quase uma trivialidade afirmar que a modernidade consiste numa aceleração generalizada dos processos de produção, de deslocamento e de comunicação. ${ }^{2}$ Nesse sentido, a máquina a vapor não apenas tornou-se uma ícone da revolução industrial por ter substituído o trabalho humano, mas também por ter revolucionado a velocidade com a qual as mercadorias passaram a ser produzidas e transportadas e à qual as pessoas eram obrigadas a se adaptar, seja na operação das máquinas, seja pelas mudanças sociais geradas por elas.

Falar em "adaptação" certamente é um eufemismo para um processo que Karl Marx comparava, na prática, com a escravidão e que descrevia, na teoria, com o conceito da alienação. Charlie Chaplin parodiava as condições do operário do capitalismo moderno em Tempos modernos com a estética do cinema mudo. Mesmo uma década depois da introdução do cinema falado, Chaplin deu preferência à pantomima, considerando o impacto do gesto como mais expressivo do que o efeito da palavra - principalmente quando se tratava de mostrar o lado desumano dessa aceleração.

Além disso, parece que a famosa cena com Chaplin na linha de montagem, que parece passar com uma velocidade cada vez maior e que não perdoa os erros do operário, não oferece tempo hábil para se expressar por meio de palavras. A própria velocidade do processo de produção se apodera do operário, de maneira que este simplesmente não tem como externar qualquer manifestação verbal, muito menos como articular qualquer reflexão sobre sua situação. A alienação denunciada por Marx passa também pela impossibilidade de reflexão e de comunicação.

É numa parêntese do seu ensaio "O narrador" que Benjamin, no habitual tom apodítico, afirma: "[...] um homem só é receptivo a um conselho na medida em que verbaliza a sua situação". " Fazendo contracenar os "tempos premodernos" com o filme de Chaplin, podemos constatar que, antes da revolução industrial, as pessoas tinham tempo suficiente para trocar conselhos e "verbalizar sua situação", pois, mesmo se o trabalho artesanal não carecia de uma certa monotonia, a convivência numa oficina não impedia que as pessoas se comunicassem; muito pelo contrário, um certo "tédio" era necessário para que as histórias viessem à tona. Não é o caso do trabalhador na indústria, que, além de solitário e desorientado, é "desaconselhado", conforme a constatação de Jeanne Marie Gagnebin em seu lúcido prefácio das Obras escolhidas. ${ }^{4}$

"No final da guerra, observou-se que os combatentes voltavam mudos do campo de batalha, não mais ricos, e sim mais pobres em experiência comunicável." $" 5 \mathrm{Se}$ alguém resolvesse filmar esse retorno dos combatentes, os recursos do cinema mudo seriam suficientes, pois esses soldados não têm mesmo nada a dizer. Por outro lado, a

Cadernos Benjaminianos, n. 3, Belo Horizonte, jan.-jun. 2011, p.63-70 
falta de palavras em um filme "falado" poderia surtir um impacto maior, pois o silêncio, nesse caso, além de ser eloquente, mas teria a força de um gesto.

$\mathrm{O}$ silêncio é uma das consequências das experiências traumatizantes da guerra - que, na terminologia benjamiana, não seriam experiências, mas apenas "vivências". A guerra é apenas a forma extrema dos "tempos modernos", pois o indivíduo, principalmente o morador das grandes cidades, se encontra numa guerra constante contra um verdadeiro bombardeio de vivências no dia-a-dia. É o grande número de "choques" que impede a consolidação da "experiência", mais exatamente da "experiência comunicável". Cabe ressaltar que, no ensaio em questão, a comunicação consiste, antes de mais nada, no ato de a pessoa "verbalizar sua situação", isto é, em sua função expressiva e representativa, conforme o modelo triádico de Karl Bühler. Ainda seguindo o mesmo modelo, a "função de apelo" seria secundária no caso da narrativa, ganhando importância somente com o surgimento da imprensa durante o século XIX. ${ }^{6}$

A mudez, portanto, não encontra suas causas apenas na guerra das trincheiras, mas numa série de outras vivências que, para "o frágil e minúsculo corpo humano", tornaram "incomensuráveis", para usar outro vocábulo preferido do dicionário de Benjamin. Os acontecimentos superaram a capacidade de assimilação das pessoas, que têm que criar mecanismos de defesa para se proteger contra o excesso de estímulos da moderna vida cotidiana. Esse escudo de proteção, porém, é insuficiente no caso de alguns acontecimentos traumáticos que deixam marcas profundas que impossibilitam qualquer verbalização.

$\mathrm{Na}$ antropologia benjaminiana, o problema mesmo são as dificuldades - ou mesmo a impossibilidade - de adaptação do ser humano às condições da modernidade que se caracterizam, entre outras coisas, pelo excesso de velocidade, pois "[...] já passou o tempo em que o tempo não contava". ${ }^{8}$ Os processos de produção não obedecem mais ao ritmo lento da fabricação manual, que era tanto a base do artesanato (Handwerk), quanto das obras de arte. O próprio parentesco etimológico entre "arte" e "artesanato" - que já não existe mais nos termos alemães Kunst e Handwerk - aponta para uma origem de ambos, a saber o trabalho manual. Conforme o ensaio sobre a obra de arte, a passagem para a modernidade seria marcada pela substituição da mão pelo olho. ${ }^{9}$

No entanto, apesar de uma zona de transição entre o artesanato e a arte, do Kunsthandwerk de um ourives, por exemplo, há uma diferença quantitativa entre o artesão e o artista que acaba se revelando como qualitativa e que se deve ao processo de individualização iniciado no Renascimento. ${ }^{10}$ Enquanto o artesão produzia, durante décadas, uma grande quantidade de mercadorias iguais e sua produção era limitada a um número reduzido de "linhas de produtos", o artista, em alguns casos, passava anos para produzir uma única obra - muitas vezes com um grande número de ajudantes anônimos. Eram anos de trabalho para produzir, manualmente, uma única obra. De certa maneira, a singularidade, que Benjamin responsibiliza pelo surgimento da aura, era reforçada pelo fato de essa obra ser fixada em determinado lugar ou de ser imóvel pelas suas próprias dimensões.

Como no caso de muitos artistas da Idade Média, quando a arte, de acordo com a tradução grega da palavra, era concebida como uma técnica, o anonimato continuou prevalecendo no âmbito artesanal, onde um grupo de artesãos "sem nome" fabricava objetos de uso em determinada quantidade, objetos que, evidentemente, eram móveis, mesmo porque tinham que ser comercializados e transportados. Ao contrário da produção artesanal, a singularidade das obras dos artistas serviu como base para a formação de uma aura que, na era pré-industrial, ainda não era perceptível porque a criação artística costumava fazer parte de um contexto religioso intrinsicamente aurático. A arte era apenas uma de várias manifestações religiosas que convergiam em um ser supremo, singular e eterno. ${ }^{11}$

Com o fim do contexto religioso como base de uma experiência universal curiosamente, Benjamin não explicita o pano-de-fundo religioso do "Narrador" - e a secularização da sociedade no decorrer de uma crescente racionalização, a arte como tal

Cadernos Benjaminianos, n. 3, Belo Horizonte, jan.-jun. 2011, p.63-70 
se isolou, sendo que a obra singular elevou esse isolamento a um grau extremo. A eternidade, até então limitado ao âmbito religioso, passou a ser um pretensão do artista, o "valor de eternidade"12 uma característica das obras singulares, que não podiam ser movimentadas, nem alteradas - e, muito menos, imitadas, pois a imitação, antes de qualquer consideração ética ou legal, representava uma duplicação, ou seja, a perda da singularidade.

A fabricação artesanal antecipou a produção em série da era industrial, uma vez que, na manufatura pré-industrial, a produção consistia na reprodução de objetos sempre iguais, sendo que não faltava o esforço de conferir aos produtos, mediante selos e carimbos, uma garantia de autenticidade e qualidade - um recurso que passou a ser substituído pela "marca registrada" da era industrial. A singularidade do selo substituia a singularidade do produto - ao contrário da obra de arte singular, onde a assinatura do artista garantia a origem pelos traços da mão, isto é, de uma mão que "originava" a obra. A rigor, essa assinatura nem era necessária, pois os mesmos traços apareciam na própria obra, fazendo com que muitas pinturas anônimas hoje podem ser identificadas pela "mão" do pintor.

Não é por acaso que Benjamin escolhe o oleiro, o "artesão plástico", por assim dizer, para mostrar que o produto artesanal, embora marcado pelas mãos, não tem como se tornar aurático pelo seu próprio caráter dinâmico, a saber: tanto pela flexibilidade do material quanto pela mobilidade do produto. Ao contrário da obra singular, criada para a eternidade e para um lugar fixo de onde não podia ser removido, o vaso, um objeto de uso cotidiano, carrega as marcas da mão, porém não como sinal da singularidade e de autenticidade, mas como prova da existência de um determinado contexto social:

Assim se imprime na narrativa a marca do narrador, como a mão do oleiro na argila do vaso. Os narradores gostam de começar sua história com uma descrição das circunstâncias em que foram informados dos fatos que vão contar a seguir, a menos que prefiram atribuir essa história a uma experiência autobiográfica. $^{13}$

As marcas das mão do oleiro, esse selo anônimo de autenticidade universal, não certificam a singularidade do produto, nem do seu criador, mas sua inserção em determinado ambiente humano - diferentemente do ambiente religioso da obra de arte singular. Não se trata, tampouco, de impressões digitais, que, na sociedade moderna e anônima, servem para identificar o autor de um crime, o infrator contra a ordem social. A marca do narrador "artesanal" apenas é um sinal de que o produto não é obra isolada de um indivíduo especialmente dotado, mas que ele surgiu de um contexto humano confiável. No anonimato da sociedade moderna, a confiança foi substituída pela prova do investigador "desconfiado", motivo pelo qual Benjamin dedica uma série de reflexões à figura do detetive e ao gênero do romance policial nos seus ensaios sobre Baudelaire (ou nos fragmentos correspondentes das Passagens). É também a razão pela qual o nosso autor chega a afirmar de que o leitor de jornal, na qualidade de um investigador leigo, procurava a verificação imediata do fato ocorrido. A informação precisa ser compreensível "em si e para si”, ${ }^{14}$ isolada de qualquer contexto humano.

A "marca" do narrador, que serve de sinal para a integração da narrativa no contexto maior da experiência, é a tradução da palavra alemã Spur, que, ainda no mesmo parágrafo, foi traduzida por outro termo em português. À maneira da "aura" ou da "experiência", a Spur também ganhou dignidade terminológica nos escritos benjaminianos, sendo que, ironicamente, a variedade das traduções do termo fez com que os vestígios para esse conceito se apagassem nas edições em português e em outros idiomas. 15

Independentemente dos problemas de tradução, há uma certa ambiguidade no próprio conceito do vestígio, pois ele tanto pode testemunhar a singularidade através de uma origem individual, quanto o caráter coletivo de um produto, como no caso da narrativa. Esta última apresenta vestígios da "experiência" quando o narrador reproduz não apenas

Cadernos Benjaminianos, n. 3, Belo Horizonte, jan.-jun. 2011, p.63-70 
a narrativa, mas também as circunstâncas em que foi contada; os vestígios são os sinais da existência dessas circunstâncias. Mais que uma vez, Benjamin insiste nos cuidados do narrador em retirar a narrativa de determinado contexto e de reinseri-la em outro. Além de ser flexível pelo seu material plástico - a linguagem -, ela possui mobilidade, podendo transpor grandes distâncias no tempo e no espaço.

"Escrevi recentemente um trabalho sobre Nikolai Leskov, que, sem reivindicar de longe o alcance daquele sobre a teoria da arte, apresenta alguns paralelos com a 'queda da aura' na medida em que a arte de narrar está acabando." ${ }^{16}$ Nesta carta a Adorno, de 4/6/1936, Benjamin diminui o valor da contribuição que ensaio "O narrador" representaria para o desenvolvimento de suas ideias - uma degradação desnecessáira, uma vez que é tão importante para suas reflexões sobre a modernidade quanto o outro, sendo mesmo indispensável para conhecer a teoria da comunicação implícita. Outra curiosidade dessa carta é a afirmação de que a questão da aura seria objeto dos dois ensaios, sendo que não há nenhuma ocorrência explícita do termo no "Narrador".

A questão da aura, entretanto, se impõe mesmo também neste ensaio, seja indiretamente pelo conceito da modernidade, seja a partir da leitura contrastiva do outro, pois o questionamento da obra tradicional no ensaio sobre a obra de arte enccontra uma série de reflexos no "Narrador", a começar pelo uso da "mão" e suas ambiguidades: por um lado, o trabalho manual e o uso (o manuseio) posterior do objeto impede o surgimento da aura, por outro lado, é o aspecto da singularidade, gerada pela mão, que faz com que Benjamin considere a obra tradicional como imcompatível com as demandas da sociedade moderna.

Certamente, a ambiguidade diminui quando se diferencia melhor entre objetos com finalidade prática e objetos que se caracterizam pela "finalidade sem fim", para usar o termo kantiano para a definição da arte. O exemplo de Benjamin é a arquitetura, ${ }^{17}$ cuja recepção pode ser tátil pelo uso cotidiano ou "ótica" a partir de uma contemplação distanciada. Assim, o morador de um palácio veneziano, por exemplo, teria uma relação diferente com sua moradia do que o turista que admira a fachada do mesmo edifício. Desde Platão, a questão do uso serviu de divisor de águas para a avaliação tanto dos objetos fabricados, quanto das obras de arte.

Entretanto, Benjamin recorre a essa diferenciação antropológica entre as diversas funções dos sentidos para estabelecer uma oposição entre a recepção "distraída" e a "concentrada" do mesmo objeto arquitetônico, defendendo, neste ensaio sobre a obra de arte tecnicamente reprodutível, à recepção distraída. Cabe lembrar que o excurso sobre a arquitetura serve para ilustrar melhor a oposição entre distração (ou dispersão - ambas as palavras são traduções do termo alemão Zerstreuung) e concentração no cinema. Dependendo dos sinônimos usados e de acordo com as traduções para diversas línguas e conforme a categoria gramatical, os dois termos opostos podem tanto se referir a um determinado estado (concentrado ou disperso) das coisas, quanto a um determinado estado psíquico (concentrado ou distraído) da pessoa. Ao contrário do caso da Spur, onde a variedade dos sinônimos dentro da mesma tradução impede que um substantivo se cristalize como um termo por meio da repetição sempre igual, a multiplicidade das traduções no caso do par distração/concentração explora uma série de opções semânticas, ilustrando, de certa maneira, uma das ideias principais do ensaio "A tarefa do tradutor", a saber, a de a tradução não empobrecer, mas enriquecer o original.

O fato de os termos em questão poderem se referir tanto a pessoas ("distraídas" por determinada obra) quanto a objetos (dispersos) contribui também para uma diluição da diferenciação convencional entre sujeito e objeto, normalmente atribuída a Descartes: a distração das pessoas - sua diversão, para acrescentar um terceiro sinônimo - responde, de certa maneira, ao aumento da oferta de opções culturais proporcionado pela reprodutibilidade técnica da obra de arte. A produção e reprodução do filme de cinema em escala industrial, denominada por Adorno, com um viés acentuadamente crítico, de "indústria cultural", ${ }_{18}$ gera uma "dispersão" que impossibilita, segundo Benjamin, a recepção concentrada do "connaisseur" da arte.

Cadernos Benjaminianos, n. 3, Belo Horizonte, jan.-jun. 2011, p.63-70 
A crítica de Adorno é compreensível e pertinente, principalmente diante das ameaças políticas dos anos 30, quando Benjamin escrevia os dois ensaios em questão. Se, para Adorno, a autonomia do sujeito era uma ilusão cartesiana, ${ }^{19}$ a redução do sujeito a um espectador de cinema exposto aos "choques", a um sujeito que não age, mas apenas reage, era igualmente inaceitável, pois esse sujeito não iria oferecer nenhuma resistência ao poder nazista da época. Pelo mesmo motivo, a "morte do sujeito", que o nazismo levava ao pé da letra nos campos de concentração, não era assunto para os pensadores da Escola de Frankfurt, ao contrário dos seus colegas franceses.

Apesar das críticas de Adorno, o ensaio sobre a obra de arte transformou-se em um dos textos fundamentais para o movimento estudantil de 68. A "destruição da aura" fazia parte de um programa anti-autoritário, mesmo se Benjamin, com exceção do último capítulo do ensaio, não tematiza explicitamente o autoritarismo em sua acepção sociológica ou política. O que desaparece com o fim da aura, não é o autoritarismo no âmbito social, mas a autoridade "da coisa", enquanto objeto estético da percepção: “[...] o que desaparece com ele [o testemunho histórico da obra de arte] é a autoridade da coisa, seu peso tradicional." ${ }^{20}$

Para Benjamin, a recepção concentrada representa uma submissão a essa autoridade daí a necessidade da "dispersão" e da reprodutibilidade técnica que é uma das razões dessa nova forma de recepção, sendo a outra o caráter "tátil" do próprio filme com seus constantes cortes que não apenas interrompem seu fluxo linear, mas ainda "golpeiam intermitentemente o espectador". ${ }^{21}$ Além disso, a recepção dispersa é marcada por uma mobilidade maior, tanto da obra, quanto do espectador - a aceleração iniciada pela máquina a vapor havia entrado numa nova fase com o uso da eletricidade e dos motores a combustão. O aumento da velocidade, por sua vez, significava que as pessoas se aproximassem com mais facilidade das obras de arte, superando assim as barreiras criadas pela auratização das obras singulares e fixas. Em outras palavras: Benjamin enquadra os obstáculos gerados pela aura numa série de pares de opostos como concentrado/disperso, dinâmico/estático, próximo/distante etc. para mostrar que a obra tradicional, pela sua própria condição material, principalmente pela sua inércia, é incompatível com uma modernidade cada vez mais "acelerada".

Cabe lembrar, no entanto, que, no ensaio "oposto" sobre o narrador, Benjamin responsabiliza a mesma aceleração pela perda da "experiência" e, consequentemente, pelo fim da narrativa. Com os dois ensaios, escritos durante os anos 1935-36, Benjamin repete, de certo modo, o jogo de oposições no plano da própria escrita. Ambos não se contradizem, apenas iluminam os lados opostos da modernização, mesmo se o autor, ocasionalmente, parece tomar partido por um dos lados, lamentando as perdas da modernização no "Narrador" e defendendo seus ganhos no outro ensaio. Se dá mais valor a este último na referida carta a Adorno, provavelmente se trata de uma concessão a uma suposta posição frankfurtiana. Na verdade, trata-se da exposição de uma ruptura intrínceca à modernidade que não se deixava costurar por meio da dialética dinâmica de Hegel, cujos pólos se uniriam na reconciliação da síntese.

Em seu último texto, "Sobre o conceito de história", as chamadas "Teses", Benjamin não sintetiza os dois ensaios, mas questiona elementos daquele sobre a obra de arte, entre eles a ideia de o ser humano ter que se adaptar à velocidade cada vez mais vertiginosa da modernidade, tão bem representada pelos Tempos modernos de Chaplin. Uma vez que o retorno à premodernidade é impossível, esse questionamento não passa pela exigência ao ritmo lento do artesão, mas pelo choque da imobilização. Nas "Teses", não se trata, portanto, de o indivíduo se adaptar aos choques que o golpeiam constantemente na vida moderna, mas da "explosão do continuum", isto é, de um dinamismo contínuo. Depois de ter postulado a "explosão" da aura, ou seja, do objeto fixo e sua continuidade estática, Benjamin se dirige, nas "Teses", contra o dinamismo gratuito que descreve como "tempo homogêneo e vazio":

Cadernos Benjaminianos, n. 3, Belo Horizonte, jan.-jun. 2011, p.63-70 
Pensar não inclui apenas o movimento das idéias, mas também sua imobilização. Quando o pensamento pára, bruscamente, numa configuração saturada de tensões, ele lhes comunica um choque, através do qual essa configuração se cristaliza enquanto mônada. O materialista histórico só se aproxima de um objeto histórico quando o confronta enquanto mônada. ${ }^{22}$

O que parece ser uma reviravolta no pensamento de Benjamin, se revela como resultado de um pensamento experimental, no sentido de explorar caminhos opostos até a última consequência. Mas esse é apenas um aspecto das aparentes contradições nos escritos benjaminianos, uma vez que as contradiões fazem parte do próprio conceito de modernidade, que, como foi apontado no início do presente ensaio, costuma se apoiar na ideia de uma aceleração generalizada. Há, todavia, uma modernidade que, num gesto de protesto contra a agitação da vida urbana, se caracteriza pelo movimento contrário à ideologia do progresso e que denuncia essa ideologia como uma forma de encobrir o que, na verdade, é uma época "homogênea e vazia". A modernidade literária fundada por Baudelaire, ao qual Benjamin dedica o maior capítulo das Passagens, se volta contra os valores pregados pela modernidade iluminista e seus continuadores do século XIX, os positivistas, que representam o alvo filosófico mais importante das Teses. Na segunda metade desse século acontece o que Thomas Anz chamou de "Lutas pela modernidade" 23 , isto é, o confronto entre aqueles que defendiam a herança do Iluminismo - para eles, um sinônimo de modernidade - e aqueles que a questionavam, autodenominando-se de "mal-ditos" e "decadentes", mas, antes de mais nada de "modernos".

Abstract: Walter Benjamin's thinking is marked by pairs of opposites, such as proximity/distance, concentration/dispersion, singularity/multiplicity, dynamism/ inertia etc. This essay intends to show that these polarities are part of a fertile dialectic, which is not, however, synthetic. Benjamin's "dialectics at a standstill" does not mend the ruptures existing in modern times, but gives evidence to its antagonistic tendencies.

Keywords: modernity, deceleration.

\section{Referências Bibliográficas}

ADORNO, Theodor W.; HORKHEIMER, Max. Dialética do esclarecimento. Trad. Guido Antônio de Almeida. Rio de Janeiro: Zahar, 1985.

ANZ, Thomas. Kämpfe um die Moderne. In: http://www.literaturkritik.de/ public/rezension.php?rez_id=12637\&ausgabe=200901 . Última alteração: 26/02/2009; último acesso: 14/04/11.

BÜHLER, Karl. Sprachtheorie. Die Darstellungsfunktion der Sprache. Jena: Gustav Fischer, 1934.

BURCKHARDT, Jacob. A cultura do Renascimento na Itália. São Paulo: Companhia das Letras, 2009.

BENJAMIN, Walter. A obra de arte na era de sua reprodutibilidade técnica. In: BENJAMIN, Walter. Magia e técnica, arte e política: ensaios sobre literatura e história 
da cultura. 7. ed., trad. Sérgio Paulo Rouanet, São Paulo: Brasiliense, 1994, p. 222-232. (Obras escolhidas; v. 1)

. Gesammelte Schriften. Vol. II/3. Rolf Tiedemann e Hermann

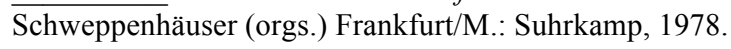

.O narrador. Considerações sobre a obra de Nikolai Leskov. In: BENJAMIN, Walter. Magia e técnica, arte e politica: ensaios sobre literatura e história da cultura. 7. ed., trad. Sérgio Paulo Rouanet, São Paulo: Brasiliense, 1994, p. 222-232. - (Obras escolhidas; v. 1) escolhidas; v. 1)

. Magia e técnica, arte e política. São Paulo, Brasiliense, 1985. - (Obras

O narrador. Considerações sobre a obra de Nikolai Leskov. In: BENJAMIN, Walter. Magia e técnica, arte e política: ensaios sobre literatura e história da cultura. 7. ed., trad. Sérgio Paulo Rouanet, São Paulo: Brasiliense, 1994, p. 222-232. (Obras escolhidas; v. 1)

. Origem do drama barroco alemão. São Paulo, Brasiliense, 1986.

Passagens. Trad. de Irene Aron e Cleonice Paes Barreto Mourão, Org. Willi Bolle e Olgária Mattos, Belo Horizonte: Editora UFMG; São Paulo: Imprensa Oficial do Estado de São Paulo, 2006.

Sobre o conceito da história. In: BENJAMIN, Walter. Magia e técnica, arte e política: ensaios sobre literatura e história da cultura. 7. ed., trad. Sérgio Paulo Rouanet, São Paulo: Brasiliense, 1994, p. 222-232. - (Obras escolhidas; v. 1)

GAGNEBIN, Jeanne Marie. Prefácio - Walter Benjamin ou a história aberta. In: BENJAMIN, Walter. Magia e técnica, arte e política: ensaios sobre literatura e história da cultura. 7. ed., trad. Sérgio Paulo Rouanet, São Paulo: Brasiliense, 1994, p. 8-19. (Obras escolhidas; v. 1)

KOSELLECK, Reinhart. Futuro passado: contribuição à semântica dos tempos históricos. Trad. do alemão Wilma Patrícia Maas e Carlos Almeida Pereira; revisão da tradução César Benjamin. Rio de Janeiro, Contraponto, 2006.

ROSA, Hartmut. Beschleunigung. Die Veränderung der Zeitstrukturen in der Moderne. Frankfurt/M., Suhrkamp, 2005.

VIRILIO, Paul. Vitesse et politique: essais de dromologie. Paris, Éd. Galilée, 1977. Le grand accélérateur. Paris, Éd. Galilée, 2010.

\section{Notas}

${ }^{1}$ Georg Otte é atualmente pesquisador visitante no Zentrum für Literatur- und Kulturforschung em Berlim.

${ }^{2}$ Cf. as publicações de Virilio, Rosa e Koselleck na bibliografia.

${ }^{3}$ BENJAMIN. O narrador. p. 200.

${ }^{4}$ BENJAMIN. Obras escolhidas. p. 11.

${ }^{5}$ BENJAMIN. O narrador. p. 198.

${ }^{6}$ BÜHLER. Sprachtheorie. Os termos alemães para as três funções são

Ausdrucksfunktion, Darstellungsfunktion e Appellfunktion. Os ensaios "O Narrador" e

Cadernos Benjaminianos, n. 3, Belo Horizonte, jan.-jun. 2011, p.63-70 
ainda "A tarefa do Tradutor" contêm in nuce uma teoria da comunicação de Benjamin, estabelecendo uma oposição entre a comunicação triádica pré-moderna e a binária da modernidade, reduzida ao modelo binário de Shannon e Weaver, que reduz a comunicação à troca de informações entre um emissor e um receptor.

${ }^{7}$ BENJAMIN. O narrador. p. 198.

${ }^{8}$ BENJAMIN. O narrador. p. 206.

${ }^{9}$ BENJAMIN. A obra de arte ... p. 167.

${ }^{10} \mathrm{Cf}$. a respeito o clássico de Jacob Burckhardt.

${ }^{11}$ Cabe ressaltar a importância da questão da singularidade no interior do âmbito religioso, a começar pela oposição entre monoteísmo e politeísmo, mas também pelas disputas teológicas em torno da questão da trindade - a dificil divisão do singular em três instâncias - , responsável por cismas e até guerras religiosas.

${ }^{12}$ BENJAMIN. A obra de arte ... p. 175.

${ }^{13}$ BENJAMIN. O narrador. p. 205.

${ }^{14}$ BENJAMIN. O narrador. p. 203.

${ }^{15} \mathrm{O}$ termo foi objeto do II Colóquio Internacional do Núcleo Walter Benjamin, realizado em novembro de 2010 na Faculdade de Letras da UFMG em Belo Horizonte, intitulado "Spuren: traços rastros vestígios".

${ }^{16}$ BENJAMIN. Gesammelte Schriften. Vol. II/3, p. 1277.

${ }^{17}$ BENJAMIN. A obra de arte ... p. 192-194.

${ }^{18}$ Cf. o capítulo "Indústria cultural" em Dialética do Esclarecimento.

${ }^{19}$ Cf. a crítica sistemática à filosofia de Descartes em "O ensaio como forma".

${ }^{20}$ BENJAMIN. A obra de arte ... p. 168.

${ }^{21}$ BENJAMIN. A obra de arte .... p. 192.

${ }^{22}$ BENJAMIN. Sobre o conceito de história, p. 231.

${ }^{23}$ ANZ. Kämpfe um die Moderne. 